difference, the law of proportionality being thus still observed. Now taking the simple arithmetical progression having for difference $\pi=3, \mathbf{1} 416$, it furnished a series of terms which markedly concord with the series of the atomic weights or equivalents as presented by Mendeleeff's Tables, and the successive blanks occurring in the series established by him in bis Tables are very approximately hlled $u p$ by the succession of the terms of this progression both as rejards numerical values and order of succession.

To demonstrate this Mendeleeff's Tables have been drawn out, with the addition opposite each equivalent of the corresponding approximate value in terms of the proyression $\pi$.

In Table I., containirig his grouping into Typical and Great Periods, there is shown the succession of the elementary bodies and their equivalents, as also the comparative concordant succes. sion of the terms of the progression $\pi$ with approximate values mostly in terms of $\frac{1}{3} \pi$.

In the Table I1., or of Periodic Series, the blanks existing in these series as indicated by Mendeleeff are shown to be very approximately filled up by corresponding terms, in value and order of succession, of the progression $\pi$. This is markedly the case as regards the gap existing between the series 8 and ro, where are wanting truelve terms, which, being filled up by successive terms of the progression $\pi$, the thirteenth term, corresponding to the equivalent of Lantharum $=180$ (?) is represented in the progression $\pi$ by the value $57 \frac{1}{3} \pi=180,1164$, or approximatively by the value $57 \pi=179,0712$.

Considering this progression of terms of $\pi$ it will be found that of the sixty-five elemeutary bodies given in Mendeleeff's Tables the following corresponding equivalents are represented, with an approximation of less than a unit, by terms of the progression :-

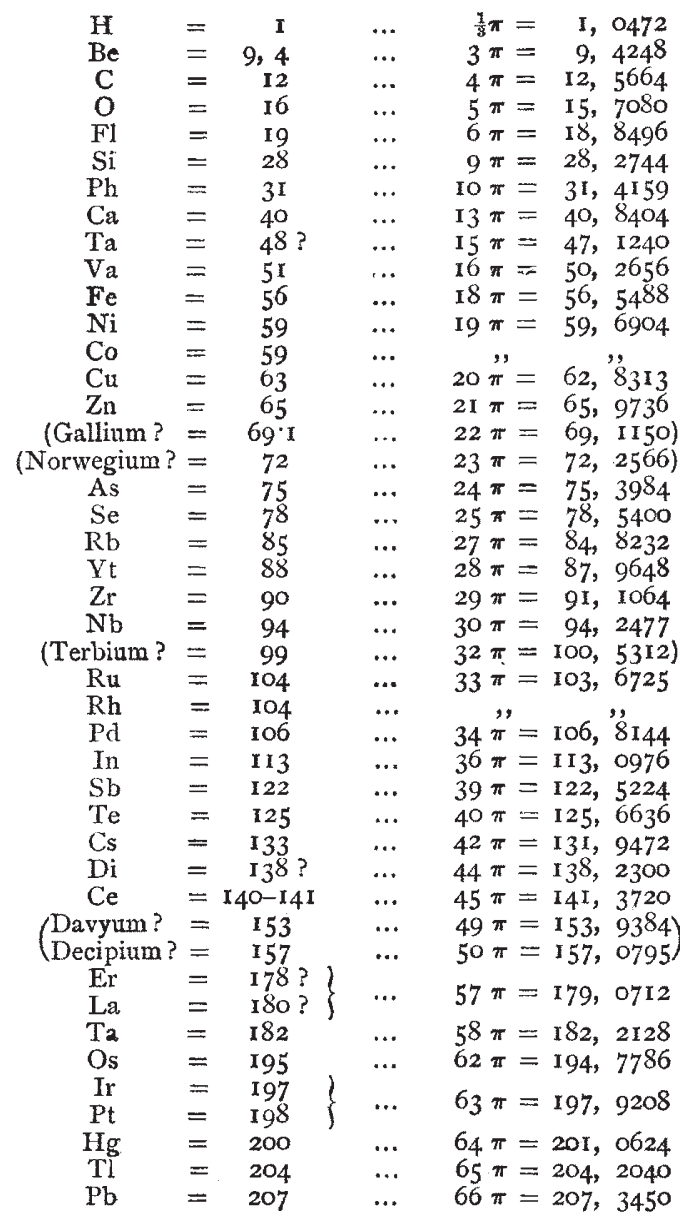

Such a concordance must be taken as some proof of the reality of a certain correspondence between the values of the equivalents and those of the terms of the progression $\pi$.

It is fully admitted that the equivalents are but relative, both as regards their number and their numerical values, to the forces which the present state of chemical analysis can bring to bear on matter, and admitting the existence of a law of progression by which the equivalents may be connected, such a progression should as a matter of necessity differ both as regards the number of representative terms and their values from the present received succession and numerical values of the equivalents, and consequently show discordances in certain places and approximate concordances in others; such is shown by the terms of the progression $\pi$.

May, 1880

J. P. O'REILtY

\section{BIRDS OF THE SOLOMON ISLANDS}

IN a paper "On the Birds of the Solomon Islands," by E. P. Ramsay, F.L.S., \&c., Curator of the Australian Museum, Sydney, read before the Linnean Society of New South Wales, February 23, I88I, the following new birds were described :-

I. Graucalus elegans, sp. nov.-A species allied to $G$, hypoleucus of Gould, but differing in its smaller size, whiter undersurface, broad jet black band on lorcal region, extending below the eye, and in having ashy grey shoulders.

2. Piczorhynchus Richardsii, sp. nov. - A remarkably distinct species, with the body and the wings and tail above black, ossified nape, and hind neck white, head and throat black, chest and remainder of the under surface chestnut; this species comes from the Island of $\mathrm{Nyi}$, and has been named in compliment to Lieut. Richards, R.N.

3. Myzomela Tristrami, sp. nov.-A jet black myzomela of large size, the bill strong and yellow, with end black, bases of the inner webs of the quills below ashy. This species is allied to, but distinct from, $M$. nigra, $M$. Forbesii, and $M$. pammelana.

4. Mygomela pulcherrima, sp. nov.-This fine species has the whole of the head, neck, chest, breast, and sides of the body and flanks, the interscapular region, rump, and upper tail coverts of a rich deep crimson, the remainder of the plumage black. The extent of the scarlet on the flanks and breast is greater than in either of the allied species $M$. cardinalis and $M$. nigriventris.

5. Zosterops (Tephras?) olivacens, sp. nov.-In this genus there is no trace of white round the eye, and the bill has quite a different contour than that of any species of the genus Zosterops. The first and sixth primary quills in this species are equal, and the third is equal in length to the fourth. The general colour above is a uniform dull brown washed with olive, inclining to smokey brown on the head, inner webs of the quills below margined with white, under surface light ashy brown, almost white on the abdomen, length about five inches.

6. Nasiterna fiuschii, sp. nov.-A very distinct species of a uniform grass-green tint, paler on the abdomen, under tail coverts yellow, length $3 \cdot 8$ inches,

The paper contains notes on six or eight other species of interest and a fine collection of Solomon Island birds were exhibited-about fifty species.

\section{OUR ASTRONOMICAL COLUMN}

The Variable Star $\chi$ Cygni.-A maximum of this variable should now be close at hand. Prof. Winnecke assiuns it to July $3 \mathbf{I}$, rather later than the average period of the last few years would give it. Its brightness at maximum has varied during the present century from $4 \mathrm{~m}$. to a very little above $7 \mathrm{~m}$. In vol. vi. of the Bonn Observations, Argelander has given nine observations of the position of this star, about which there has been so much and unnecessary confusion. Its place for $1880^{\circ} 0$ is in right ascension I $9 \mathrm{~b} .45 \mathrm{~m} .57^{\circ} 33^{\mathrm{s}}$., declination $32^{\circ} 36^{\prime} 42^{\prime \prime} \cdot 1$. A comparison of Lalande's observation in 1793 with Argelander's shows that there is no appreciable proper motion. The variability of $\chi$ Cygni was discovered in 1686 by Kirch, whose first observed maximum is dated November $28,1687$.

COMET I88 I 6. - It appears this comet was detected at Sydney as early as May 22, so that we may yet receive observations from the Australian observatories made nearly a week before the first of those made at Rio Janeiro. The orbit, founded upon postperihelion places, which we published last week, gives the comet's place on May 22 at ro p.m. at Sydney in right ascension $4 \mathrm{~h} .58 .5 \mathrm{~m}$., declination $35^{\circ} 33^{\prime} \mathrm{S}$., and at this time the comet was distant from the earth $0^{\circ} 772$ of the earth's mean distance from the sun. M. Cruls' first position, deduced from the observations at $R$ io is as follows :- 